\title{
ESTUDANTES DE ENFERMAGEM ASSISTEM CRIANCCAS DOENTES UTILIZANDO «ENTREVISTA COM BRINCADEIRA»
}

\author{
Esther Moraes: \\ Marina Silvestre Correa** \\ Silvia Maria Gabric $* * *$ \\ Valéria Castilho*:***
}

MORAES, E.; CORREA. M. S.; GABRIEL. S. M. \& CASTILHO, V. Estudantes de enfermagem assistem crianças doentes, utilizando "entrevista com brincadeira". Rev. Esc. Enf. USP, São Paulo, 13(1):29-39. 1979.

Apresenta-se e comenta-se " significado da utilizaçâo de "entrevista com brincadeira", ‘m três situaçôs de assistência a crianţ̧as dontes.

\section{INTRODUÇĀO}

Na disciplina Enfermagem Pediátrica, aconselhamos os alunos a utilizarem o brinquedo como um recurso auxiliar da enfermagem na assistência de crianças sadias e doentes. Focalizamos. principalmente. o papel do brinquedo no desenvolvimento de capacidades novas e no ajustamento da criança às situações do meio ambiente em que vive

Em relação ao desenvolvimento, os alunos são estimulados e orientados a utilizar o brinquedo para encontrar os marcos do desenvolvimento de determinada criança e para promover o seu avanço no desempenho de novas capacidades. Com tais objetivos, todos os grupos de estudantes são levados a fabricar brinquedos im. provisados com material caseiro e hospitalar descartável. Nessa atividade, descobrem o papel do brinquedo na determinação do nivel de desenvolvimento de uma criança e o valor que apresenta como fator de progresso em vários espectos do comportamento.

Observam também a repercussão, na equipe de saúde de uma unidade, da emergência de comportamentos novos nas crianças estimuladas. Todos nós sabemos que algumas crianças, por vários motivos. se manifestam psico-socialmente, na enfermaria. de forma pouco sensível para as pessoas. A maior conseqüência da estimulação pelo brinquedo, em relação a essas crianças, é que, exercendo elas novas atividades, o número de contacto significativos com o pessoal da clínica aumenta e estabelecem-se canais de comunicação de uma a outra parte.

Outra perspectiva da utilização do brinquedo em enfermagem pediátrica apresentada aos alunos é a de servir como meio de comunicação entre o enfermeiro e a criança. Para essa finalidade, o brinquedo é utilizado $\mathrm{cm}$ duas situações principais: preparo para procedimentos e descoberta de necessidades e/ou dificuldades da criança hospitalizada, encobertas para o enfermeiro.

\footnotetext{
* Professor Assistente Doutor da disciplina Enfermagem Pediátrica da EEUSP.

* * Enfermeira, chefe do serviço de Enfermagem do Hospital Maternidade Morumbi.

*** Professora do Curso Técnico de Enfermagem do Colésrio Técnico Estadual "Carlos de Campos".

**** Estudante do Curso de Graduação da EEUSP
} 
$\mathrm{Na}$ primeira situação, os estudantes aprendem a dramatizar procedimentos de diagnóstico e tratamento, com material hospitalar real envolvido na experiência e com animais e bonecos representando familiares e pessoal da equipe de saúde. Essa atividade é programada por todos os alunos, que a desenvolvem em unidades de cirurgia, local onde os procedimentos. ameaçadores para a criança, são mais freqüentes.

A nossa experiência tem sido a de quc, em geral, os alunos reconhecem a superioridade da abordagem das crianças por meio de dramatização sobre a abordagem unicamente verbal. Sentem que os pacientes pré-escolares percebem melhor o que vai acontecer com eles, interpretam mais positivamente a experiência a ser vivida e a função real, não fantasiada, do material hospitalar e das técnicas empregadas durante um procedimento. Além disso, a criança fica avisada de que talvez sofra um pouco, aprende como participar na experiência, é informada de que pode expressar sentimentos de qualquer tipo e ainda ser bem sucedida aos olhos da equipe de saúde, mesmo que sua cooperação venha a ser nula. De outro lado, o aluno capta particularidades do pensamento e dos sentimentos da criança, quando a observa repetir um procedimento, porque ela projeta de modo evidente e enfático em sua representação, por meio de ações e verbalizações, o modo como deseja ser tratada numa experiência desagradável: ser bem anestesiada, bem coberta, bem suturada, tratada com bastante carinho. Da dramatização de um procedimento por um paciente, os alunos concluem que parte das informações foi ou não assimilada, aspecto esse que, via de regra. escapa ao controle do enfermeiro, já que as crianças não manifestam. muitas vezes, espontanamente e abertamente, o que estão pensando ou sentindo e, muito inenos, respondem de maneira satisfatória a perguntas diretas.

Na segunda situação da aplicação do brinquedo como auxiliar de comunicação entre o enfermeiro e a criança, é apresentada aos alunos a técnica de «entrevista com brincadeira» de acordo com ERICKSON (1958).

Se, na aplicação anterior, o efeito do brinquedo dramático é prevenir desajustes emocionais e diminuir traumas psicológicos oriundos da vivência de experiência desagradável, o emprego da «entrevista com brincadeira» permite à criança expressar sentimentos reprimidos, projetar necessidades, encaminhar e descobrir soluções para seus problemas.

Do ponto de vista didático, a aprendizagem das técnicas da brincadeira nãodirigida, na presença de um adulto, simpático para a criança, tem possibilitado aos alunos a compreensão de necessidades menos óbvias e a identificação de problemas mais ocultos, apesar da imaturidade emocional, dil linguagem e capacidade cognitiva das crianças de dois a doze anos, faixa etária da nossa experiência.

São bem conhecidas as interpretações dadas ao significado do brinquedo dramático. Segundo FREUD (1950), a criança repete no brinquedo tudo quanto a impressiona; assim fazendo, torna-se dona da situação, passa de posição passiva para ativa, de agredida a agressora. Para PIAGET (1951), a criança assimila situações dolorosas com participação total do seu ego, pela reprodução, na brincadeira, das situaçães desagradáveis. Acredita que a repetição tem a finalidade de tornar a dor mais suportável. Comparativamente, chamamos a atenção para o comportamento do adulto que sofre uma frustração ou vive um conflito: procura uma pessoa amiga, expõe a situação que o aflige e repete essa exposição até que supere ou resolva seu problema. 
ERIKSON (1971) focaliza a importância de a criança brincar sozinha na presença de um adulto simpático. Para esse autor, o adulto representa um porto seguro onde a criança pode rever as emoções já vividas em situações difíceis. Brincar é a maneira mais natural de a criança «autocurar-se».

\section{«ENTREVISTA COM BRINCADEIRA»}

O ensino das técnicas da «entrevista com brincadeira» tem proporcionado aos alunos experiências gratificantes e significativas. Após superar uma resistência normal para desempenhar um papel novo. o aluno percebe, em uma sessão de brincadeira, os aspectos de diagnóstico e de terapia do procedimento. Presencia uma seqüência de comportamentos que é aproximadamente assim: timidez; aumento de espontaneidade; expressão de sentimentos, desejos e necessidades, graças à dramatização de situações já vividas ou a serem vivenciadas; clímax de bem-estar e alegria, quando a criança exterioriza alguma coisa que lhe fazia mal ou perebe algo novo ou de valor para si. A criança, parece, mostra o crescimento do scu eu. Freqüientemente, o aumento de energia nas crianças, durante o período de brincadeira na presença de um adulto aceitador, faz que elas empurrem e «toquem» cutras crianças que, por ventura, tentam «invadir» a sessão de brincadeira.

Em resultado da entrevista, os alunos percebem com nitidez a qualidade particular da assistência que determinado paciente necessita e observam mudanças na criança, assim que implantam um relacionamento adequado para atender às necessidades compreendidas

Vemos a «entrevista com brincadeira» como um recurso sem igual para colocar em foco, para o estudante. aspectos que a experiência e o conhecimento do professor quase nada podem fazer, isto é, a «entrevista com brincadeira» torna os alunos sensiveis às verdadeiras necessidades da criança e fá-los aceitar os pacientes mais difíceis, de comportamento socialmente inaceitável, ao invés de rejeitá-los.

Quando às técriicas propriamente ditas, os alunos, de acordo com MOUSTAKAS (1973), AXLINE (1972) e ERICKSON (1958), são orientados a adotar certas atitudes e tipos de conduta, com o objetivo de a criança brincar com inteira liberdade; ou seja: a entrevista não é imposta, ela é convidada a brincar; sua brincadeira não é aprovada ou desaprovada: a criança e a sua brincadeira são aceitas; as perguntas da criança são devolvidas, para que ela mesma tome qualquer decisão. Os alunos são estimulados a observar e registrar todos os comportamentos manifestados pela criança durante a entrevista e não devem dirigir a brincadeira.

Na primeira entrevista, o material é apresentado à criança mas não é identificado. Consta de bonecos de pano, de $15 \mathrm{~cm}$ de altura, representando adultos, e de bonecos menores, representando crianças. Alguns reproduzem familiares; outros, pessoal hospitalar. Os bonecos são acompanhados de objetos domésticos e hospitalares.

O local e o horário para a entrevista vêm sendo selecionados pelo critério da possibilidade de evitarem interrupçōes; nossos alunos têm utilizado o leito do paciente, a mesa da enfermaria e qualquer dependência da unidade disponível por um período de 45 a 60 minutos.

Quanto às indicações, temos aconselhado os alunos a aplicarem a «entrevista com brincadeira» quando encontram dificuldade na compreensão ou aceitação do 
comportamento de uma criança. A freqüência das entrevistas tem sido determinada pelos estudantes e pelas crianças: quando sentem necessidade, repetem as sessões de brincadeira até que se resolva a situação problemática; outras vezes, são as próprias crianças que pedem para brincar com as «bruxinhas».

Visando ilustrar o valor e a simplicidade do processo que utiliza a brincadeira para conhecer a criança $e$ a fim de auxiliá-la a falar, a compreender uma situação difícil e a ajustar-se a ela, apresentamos, em seguida, o relato da experiência de três alunas que cursaram a disciplina Enfermagem Pediátrica nos anos 1973, 1977 e 1978 .

\section{RELATO DE TRES «ENTREVISTA COM BRINCADEIRA»}

\section{ENTREVISTA N. ${ }^{1}$}

\section{ALUNA: Marina Silvestre Correa}

\section{Antecedentes da aplicação da «entrevista com brincadeira»}

Fui encarregada de fazer um estudo de relacionamento com V., uma menina de cinco anos. na segunda semana de hospitalização, que estava em fase de exames preparatórios para correção cirúrgica de comunicação interventricular.

Minhas impressões, depois do primeiro dia de relacionamento, foram de que algo a afligia, deixando-a ansiosa, cheia de temor. Observei que se preocupava com aquilo que as outras crianças da enfermaria poderiam estar sentindo em exames e no pós-operatório. $\mathrm{O}$ assunto de sua doença irritava-a. Após o almoço, disse que ia para a cama mas que não dormiria. E comentou: «Pensa que eu não sou sabida?». Provavelmente, essa observação estava relacionada com o cateterismo cardiaco, ventilado em sua presença durante a visita médica, a ser feito caso ela melhorasse da tosse.

No dia seguinte, observei V. ser informada de que faria o cateterismo. Devido à falta de preparo psicológico para aquele exame, novamente apresentou manifestações de tensão emocional, com o uso constante de chupeta, embora a prova tivesse sido suspensa pelas condições pulmonares da menina.

No terceiro dia de cuidados, planejei ajudar V. a verbalizar as suas dificuldades, desejos e sentimentos. Com tal objetivo, induzi-a a brincar.

\section{«Entrevista com brincadeira»}

Sobre pequena mesa de cabeceira da enfermaria de V. coloquei o seguinte material: telefone, panelinhas, quebra-cabeça, seringa, agulha, frasco-ampola, a]godão e bonecas. Sentei-me numa cadeira e o brinquedo começou.

V. - Vamos brincar de telefone, S.? (S. é outra paciente da enfermaria.)

S. - Vamos.

V. - Alô! Quem fala? Traga suas filhas ao hospital.

S. - Para quê?

V. - Para serem operadas.

S. — Quem está falando?

V. - A «doutora médica»!

S. - Quanto tempo vai demorar?

V. - Cinco horas. 
S. - «Tá» bom.

(Silêncio.)

S. - Onde ela vai ser operada?

V. - No peito.

Pegou a seringa. Colocou água no frasco-ampola e aspirou, com gestos dificultados pela falta de prática. Em seguida picou o meio do braço de uma boneca, explicando:

V. - É a anestesia.

V. - Tia, «tem» álcool? Precisa passar álcool para não doer.

Apanhou o algodão e, com movimentos suaves, passou-o na boneca.

V. — «Tá» doendo? Coitada!

Em seguida, ao telefone, disse:

V. - Aqui é a Doutora V. (Sua fisionomia era séria.) A senhora pode vir buscar a sua filha, que ela já vai sair.

S. - Mas você não a operou?

V. - Esta não precisa. Só a outra.

Pegou uma segunda boneca, tirou-lhe o vestido. Apanhou dois palitos e enfiou-os nas costas da boneca, com agressividade.

(Silêncio.)

V. - Ela vai fazer o cateterismo.

S. - O que é isso, doutora?

V. - É cortar a perna.

Fez, do palito, uma faca imaginária e ia aproximar-se da perna da boneca, quando seu médico se dirigiu a ela. V. largou a brincadeira timidamente. Com rapidez cobriu a boneca que estava nua, e debruçou-se sobre os brinquedos. Ficou assim. até que o doutor se retirou da enfermaria. Então voltou à atividade:

V. - Pronto! Acabei. Você! (Apontou para S.) Pode levar sua filha.

S. - E a outra? Você não vai operá-la?

V. - Não. A outra não precisa.

Guardou todo o material. Depois, dirigindo-se à porta da enfermaria, observou:

V. - Ah! Estou tão cansada!

\section{Comentário}

Considerei o comportamento de V. normal, pois toda criança tem medo de injeção, de exames e de cirurgia. A falta de orientação juntamente com a fantasia. característica de sua idade, estavam tornando V. tensa e sem muitas possibilidades de descarregar suas emoções. À medida que foi adquirindo confiança em mim e que foi tendo meios de comunicar-se, conseguiu exteriorizar com clareza os motivos pelos quais acumulara tanta tensão emocional: V. entendia «cateterismo» e «cirurgia» como experiências agressivas e perigosas para a sua integridade física. A paciente projetou, também, na brincadeira, um mecanismo de defesa, de fantasia, que estava utilizando para enfrentar as experiênicas desagradáveis, pelas quais sabia que deveria passar durante a sua hospitalização. 
Infelizmente a assistência foi interrompida devido à alta que foi dada a V.. para tratar-se em casa do estado gripal em que se encontrava.

FNTREVISTA N. 2

\section{ALUNA: Sílvia Maria Gabriel}

Antecedentes da aplicação da «entrevista com brincadeira»

Dona I. estava na sala de medicação de um ambulatório pediátrico de emergência. com R., que havia recebido «Plasil». A queixa de Dona I. era a de que a filha. criança de cinco anos. se recusava a alimentar-se e, sendo forçada, vomitava. Referiu que a garota só aceitava água; às vezes, algum doce. Disse que ela. a mãe. «fazia de tudo» (contava estórias, andava atrás da menina com alimentos), mas que a pequena só comia quando o pai ia visitá-la. A filha mais velha de Dona I., ao contrário. estava comendo demais. A mãe contou que tudo havia começado, assim que seu marido deixara a casa. Nessa ocasião, fora orientada a procurar um serviço de saúde mental infantil e a não forçar a alimentação.

Na semana seguinte encontrei-me ocasionalmente com $R$. e sua mãe, no mesmo ambulatório pediátrico de emergência. A queixa foi que, agora, $R$. não se alimentava nem mesmo no dia em que o pai visitava as filhas; ficava agarrada a ele todo o tempo e, ao se despedirem, chorava muito e agredia a mãe com pontapés. Em um mês, a criança havia perdido dois quilos.

Nesta segunda oportunidade tentei conquistar a simpatia de R. Ela não mt respondia e olhava-me com reserva. Observei que sua aparência era saudável, embora expressasse certa ansiedade, chupando o dedo constantemente. Inventei um. pretexto e pedi à mãe que me deixasse a sós com a filha.

\section{«Entrevista com brincadeira»}

S. - R., agora a mamãe vai conversar com a médica. Enquanto isso, posso ficar com você. Quer?

$R$. nada respondeu, mas continou a olhar-me.

S. - Veja: nesta sacola há alguns brinquedos. Vamos brincar?

A mãe ajudou.

D.I. - Que bom, filhinha! Aproveite para brincar um pouco, enquanto falo com a médica.

A mãe levantou-se. Como R. não apresentasse resistência, peguei-a pela mão e dirigimo-nos às proximidades de uma rouparia. No caminho, $R$. chupava o dedo e olhava para a sacola de brinquedos.

S. - Pronto, R.! Pode pegar o que quiser, da sacola.

Sentei-me e fiz que lia um caderno. R. hesitou um pouco. Olhava para mim e para a sacola, alternadamente. Abriu a sacola e, antes de retirar os brinquedos. indagou:

R. — Você não disse que ia brincar comigo? 
S. - Você quer? Eu gostaria muito!

R. - E do que vamos brincar?

S. - Do que você quiser.

Retirou os brinquedos, espalhou-os pelo chão e continuou:

R. - Vamos brincar de casinha? (Falou com insegurança.)

S. - «Oba»! Vamos, sim.

R. - Vamos ser comadres?

S. - Vamos. Mas como é «ser comadre»?

R. - Ah! Então você não sabe? (Perguntou com ar de impaciência.) Comadre é uma «gente» com que «a gente» conversa, que a «gente» visita...

S. - Ah! Já sei.

R. passou a dividir as panelinhas comigo e, diante das bonecas, observou:

R. - Eu queria fazer de conta que estas duas eram minhas filhas. Mas aí não sobraria para você.

S. - Dou um jeito. bebê.

Peguei algumas roupas, fiz um embrulho e envolvi-o em cobertorzinho para

S. - Faz de conta que esta é minha filha.

R. mostrou-se satisfeita e passou as duas bonecas para o seu lado.

R. - E agora? Só temos um telefone.

S. - Então esse é seu.

Mostrei-lhe um frasco de soro vazio:

S. - E este aqui é o meu telefone.

Pausa.

Com um gesto, tracei uma linha imaginária:

S. - Deste lado é a minha casa; desse, a sua. Está bem?

Daí a pouco, R., de costas para mim, pegou o telefone.

R. - Trrimm! Trrimm!

S. - Alô!

R. - Quem é?

S. - Aqui é a Silvia. É você, comadre?

R. - É.

S. - Como vai?

R. - «Tô» boa. O que você está fazendo, comadre?

S. - Estou terminando o almoço. A minha filha come tanto! E você, comadre, o que está fazendo?

R. - Eu também estou acabando de fazer o almoço.

S. - A senhora tem que fazer mais comida do que eu, não? Tem duas filhas. não é?

R. - É. Eu faço bastante, mas só a «mais grande» come tudo e repete. Ela come, come!

S. - E a mais nova? A senhora não dá comida para ela?

R. - «Dô», mas ela não come. 
S. - Será que ela não come mesmo?

R. - Bem, eu não vejo. Na minha frente ela não come nadinha.

S. - Por que será, comadre?

R. - Sabe?

R. pensa.

R. - É que seu pai foi viajar. Ela só vai comer, quando ele voltar.

S. - Ah! Entendo. Mas, se ele demorar um pouco para voltar? Ela vai ficar fraquinha. Você não acha, comadre?

R. - Se ela estiver fraquinha, ele «leva ela» para passear de carro. compra sorvete para ela .. e aí também ele nunca mais viaja.

S. - Ah! Sim.

Pausa.

R. - «Tchau», comadre. (R. desliga o telefone.)

S. - «Tchau», comadre.

\section{Comentário}

Essa experiência demonstrou a validade da brincadeira para se descobrir os sentimentos de uma criança e para, posteriormente. ajudá-la em suas dificuldades. A paciente R. revelou. brincando. as causas de sua ansiedade e demonstrou seu «jogo» para enfrentar a separação do pai. $O$ que não teria sido dito em 24 horas de convivência com um adulto. pôde ser revelado em trinta minutos de «entrevista com brincadeira».

ENTREVISTA N. 3 ALUNA: Valéria Castilho

Antecedentes da aplicação da «entrevista com brincadeira»

A paciente L., de quatro anos de idade, sofrera três quedas aos dois anos e quatro meses. Desde essa data. passou a apresentar dificuldade em locomover-se. Atualmente. foi hospitalizada com este quadro clínico: anorexia ,irritabilidade, parada de crescimento, perda de peso, hipotonia. poliúria, dificuldade para manter-se em pé e andar, rosário raquítico. alargamento epifisário e encurvamento diafisário. Foi diagnosticado raquitismo resistente à Vitamina $\mathrm{D}$, devido à acidose renal tubular.

Quando cheguei, pela manhã, à enfermaria, aproximei-me do berço de L. que estava acordando. Olhou para mim e, com fisionomia triste e chorosa, disse: «Tia. hoje eu quero que ninguém ponha a mão em mim. Só você, para «banhar eu».

Nisso, entrou a médica para examiná-la. L. recebeu-a com choro e, batendo em suas mãos. nãa permitiu ser tocada.

Não quis brincar na sala de recreação, onde tanto gostava de ficar. Vendo a tensão emocional e a agressividade que $L$. estava apresentando, resolvi oferecer-lhe brinquedos para que ela pudesse dar vazão às suas emoções e eu me orientasse sobre o que estava ocasionando aquele comportamento.

«Entrevista com brincadeira»

Apresentei a L. o seguinte material: boneca, cuba rim. 2 pedaços de gaze. sa- 
bão e uma fralda. L. estava sentada no leito. A fisionomia era séria. Sentei-me numa poltrona, perto da sua cama.

L. pegou a boneca, olhou-a e disse:

L. -- Vou banhar a cabeça dela: tem lêndea.

Passa sabão nas mãos e ensaboa os braços e pernas da boneca.

L. - «Fica» certa! (Ordena brava para a boneca, que está com as pernas viradas para trás.)

Volta-se para mim e comenta:

L. - Ela também nãus fica em pé. Acho que ela também não anda.

Passa novamente sabão nas mãos e ensaboa o rosto da boneca.

L. - A boneca não fecha o olho. $\mathrm{O}$ olho dela «tá» ardendo. Tia, você não deixa o meu olho arder, não!

Mostra-me as suas mãos que se encontram cheias de sabão. Continua fazendo espuma na cabeça da boneca. Depois, segura-a pelas pernas e mergulha a cabeça dela na água para retirar o sabão. Pega um pedaço de gaze, que começa a lavar e torcer. Esfrega a boneca com uma compressa de gaze.

L. - Tia, o olho da boneca está com sabão.

Molha a mão na água e passa as pontas dos dedos nos olhos da boneca (do mesmo modo como eu fazia com ela).

L. - Estou banhando a minha boneca. (É o que diz para um médico que entra na na enfermaria.)

Não deu maior atenção a ele e continuou a brincar.

L. - Tia, onde está a calça da boneca? Ela já está limpa. A cabeça dela agora «tá» limpa. Não tenho pente. Olha como ela está! Olha as pernas dela: não fica em pé.

Acerta as pernas da boneca e coloca-a em pé. segurando-a com as mãos.

L. - Está molhando a minha aliança. Vou tirar para não molhar.

Coloca a boneca de lado e lava a aliança (uma argolinha que ela usa no dedo).

L. - Minha mão agora «tá» limpa, tia.

Mostra as mãos para mim.

L. - Vou tirar a boneca (que está dentro da cuba rim). Pode tirar, Tia"

Segura a boneca no ar e olha para mim.

V. - Você é quem sabe.

Ela pensa e resolve:

L. - Vou colocá-la aqui ao lado.

Pega uma compressa que começa a lavar e torcer.

L. - Vou pendurar.

Abre a gaze e pendura-a na grade do berço. 
Olha para mim, que estou escrevendo.

L. - Tia, «bota» o meu nome aí.

Continua a lavar outro pedaço de gaze. Pega a fralda e estende-a na cama. Deita a boneca sobre a fralda e começa a enxugá-la na mesma seqüência e do mesmo modo que eu a enxugava. Brinca de esconde-esconde com uma ponta da «toalha», como eu fazia com ela. Pergunta para a boneca onde está. Levanta a fralda e diz: «Achou!», rindo muito.

L. - Vou vestir a calça. A calça dela é pequena, não é?

Começa a vestir a calça. Pára. Olha para mim e pergunta:

L. — Tia, você é minha amiga? dizendo:

Respondo que sim. Ela olha outra vez para a boneca e tenta vestir a calça,

L. - Aqui, um buraco e aqui, outro buraco.

Era o que eu fazia, quando a vestia. Larga a boneca e encerra:

L. - Tia, já acabei. Você me leva «na salinha» (sala de recreações)?

\section{Comentário}

A paciente demonstrou o que pensava e sentia em relação às suas pernas. Além disso, pude verificar que a brincadeira levou L. a perceber que o banho dado por mim se caracterizava por grande cuidado, aspecto esse provavelmente relacionado à pergunta a respeito de eu ser sua amiga. A mudança na fisionomia e no estado emocional de L. foi muito grande.

Observe-se, porém: nunca peguei L. pelas pernas e a enfiei de cabeça na água, para enxaguar os seus cabelos. Talvez ela tivesse tido essa experiência, com outras pessoas.

\section{COMENTÁRIO SOBRE O SIGNIFICADO DAS ENTREVISTAS}

Em primeiro lugar, ressaltamos que as «entrevistas com brincadeira» ocorreram de forma casual e por iniciativa das alunas. Esse é um fato raro, já que a resistência para utilizar o brinquedo é o comportamento mais normal entre os alunos.

Tecnicamente falando, nas três experiências, as alunas adaptaram e improvisaram material, atitudes e condutas para realizarem as entrevistas. Mas, como diz MOUSTAKAS (1973), mais importante que as técnicas é o relacionamento que se estabelece entre terapeuta e paciente. E, como diz BARTON (1969), as maneiras como as técnicas de brinquedo utilizadas ou para fins de diagnóstico, ou de terapia, são muitas, variadas e somente encontram limite no conhecimento, na habilidade e na imaginação da enfermeira.

A seleção dos brinquedos, de certa forma, influenciou a natureza e o conteúdo da brincadeira das crianças. $\mathrm{Na}$ entrevista $n .^{\circ} 2$, houve participação ativa da aluna em toda a sessão de brincadeira. Normalmente, tal não acontece: a criança sozinha é que idealiza e realiza a sua brincadeira. No entanto, pode-se considerar que a comunicação das três crianças foi o resultado de uma brincadeira não-dirigida. 
As alunas forain felizes em reconhecer a oportunidade de ser aplicada a «entrevista com brincadeira». Percebendo tensão nas crianças, sinal de bloqueio de comportamento e indicador de desajustamento, utilizaram, conscientemente, a forma ideal de comunicação para se obterem dados íntegros sobre pensamentos e sentimentos de crianças.

Como se pode verificar. a sessão de brineadeira, sem perda de tempo permitiu às pacientes focalizarem seus problemas e conflitos: cirurgia e cateterismo, separação do pai, incapacidade para ficar em pé e andar. As duas primeiras entrevistas deram oportunidade às crianças de demonstrarem suas reações de defesa, para enfrentar, cada uma, o seu sofrimento. Naturalmente, o clima da entrevista foi de desabafo e de mal-estar. A entrevista $n .^{\circ} 3$, sem dúvida, produziu um resultado gratificante para a criança e para a aluna. A paciente L.. após representar o papel de uma enfermeira, que dá banho com carinho, identifica no meio hospitalar uma pessoa amiga. Essa paciente, também na brincadeira, fala de sua incapacidade de ficar em pé e andar. Significa que a brincadeira a está ajudando a enfrentar a realidade de seu problema físico.

É fácil deduzir-se que as alunas, após compreenderem o modo pelo qual as rrianças estavam vivendo determinada situação, deveriam utilizar as informações colhidas para, a partir delas e com a colaboração da equipe de saúde e dos familiares das pacientes, organizarem uma assistência adequada e eficaz.

Finalizando, dizemos que o brinquedo, nas mãos de enfermeiro e utilizado de forma consciente passa a ser um instrumento criativo. tanto para ele como para a uriança, porque reestrutura a compreensão de ambos.

MORAES, E.; CORREA. M. S.; GABRIEL. S. M. \& CASTILHO, V. Nursing students help sick children through "play-interview". Rev. Esc. Enf. USP, São Paulo, 13 (1): 29-39, 1979.

Presenting and commenting on the significance of the employment of "play-interview" in the situations of aid to sick children.

\section{REFERENCIAS BIBLIOGRAFICAS}

AXLINE, V. M. - Ludoterapia. Belo Horizonte, Interlivros, 1972. $351 \mathrm{p}$.

BARTON, P. H. - Nursing assessment and intervention through play. In: BERGERSEN, B. S. et alii Current concepts in clinical nursing. Saint Louis, Mosby, 1969. p. 203-7.

ERICKSON, F. H. - Play interviews for four-year-old hospitalized children. Lafayette, Child Develop. ment Publications, 1958. p. 22 e 23.

- Infância e sociedade. 2. ed. Rio de Janeiro, Zahar, 1971. p. 203-4.

MOUSTAKAS, C. E. - Psychotherapy with children: the living relationships. 3. ed. New York, Ballantine Books, 1973. $366 \mathrm{p}$.

PIAGET, J. - Play, dreams and imitation in childhood. New York, Norton, 1951. p. 148-9. 